University of Nebraska - Lincoln

DigitalCommons@University of Nebraska - Lincoln

April 1953

\title{
Use of a Simple Blowing Device to Facilitate Inspection of Wheat For Internal Infestation
}

Max Milner

Kansas State College, Manhattan, Kansas

E. P. Farrell

Kansas State College, Manhattan, Kansas

Robert Katz

University of Nebraska-Lincoln, rkatz2@unl.edu

Follow this and additional works at: https://digitalcommons.unl.edu/physicskatz

Part of the Physics Commons

Milner, Max; Farrell, E. P.; and Katz, Robert, "Use of a Simple Blowing Device to Facilitate Inspection of Wheat For Internal Infestation" (1953). Robert Katz Publications. 96.

https://digitalcommons.unl.edu/physicskatz/96

This Article is brought to you for free and open access by the Research Papers in Physics and Astronomy at DigitalCommons@University of Nebraska - Lincoln. It has been accepted for inclusion in Robert Katz Publications by an authorized administrator of DigitalCommons@University of Nebraska - Lincoln. 


\title{
USF (OF A SIMPILE BLOWING DEVICE TO FACILITATE INSPECTION OF WHEAT FOR INTERNAL INFESTATION*
}

\author{
By Max Milner, $\dagger$ E. P. Falrzhl, $\dagger$ and Roblizt Katz $\ddagger$, \\ (Kansas State College, Manhattan, Kansas)
}

Enforcement of sanitary practices in the commercial handling of wheat, particularly with reference to insect infestation, recquires a method of inspection of whoat for internal or hidden insect infestation which is reliable, yet rapid enough for routine use. A number of inspection methods have been developed for this purpose, and a review has been published (1) of those proposed up to two years ago. A rigorous evaluation of several of these technies has been made recently (2).

The rapid inspection method suggested to the grain trade by the Food and Drug Administration (2), based on the results of an extensive study of the sources of insect fragments in mill products (3), involves gross examination of 100 grams of wheat for insect exit holes. More than three of such insert-emerged kernels in the sample indicate excessive internal or hidden infestation. This inspection method has been criticized as too timeconsuming, and difficulty has been experienced in differentiating exit holes from deep insect feeding punctures.

An adjunct to the emergence hole test has been proposed by the Bureau of Entomology, United States Department of Agriculture (4), which involves the use of a solution of ferric nitrate as a flotation medium to cause the insert-emerged kernels to float to the surface. A device designed to farilitate the examination of grain samples for insert exit holes consists of a glass tray upon which the grain is placed and about which are arranged lights and mirrors so oriented that the inspector can view all surfaces of the kernels on the tray without manipulating them.\$

Previous studies at Kansas State College on the problem of detection of internal infestation have led to the development of a fluorescent staining technic essentially specific for insect egg plugs (5), an X-ray inspection procedure ( $(j-8)$ whic $h \mathrm{j}$ s gaining widespread use in the milling industry and grain trade for inspertion of grain in car-lot quantities, and an aural detection method using clectronic technics (9) which shows considerable promise for evaluating the effectiveness of fumigants and for research studies on internally feeding inserts.

The present rommunication deals with the discovery that a simple blowing device commonly used in seed testing laboratories' may be em-

\footnotetext{
* Contribution No. 237, I)epartment of Flour and Feed Milling Industries and No. 39, 1)epartment. of Physies, Katnsils Agricultural Experiment Station.

+ Depurtment of llour and Ferel Milling Industries.

I I) epirtment of I'hysios.

This deviee is manufacelured by the stcedman Iaboratorice, Kansas City, Mo. urid.

i In these experiments a matehine manuficet ured by the Ames Powercount (Co. of Brokkings, s. 1)., was
} 
ployed to produce a rapid and fairly quantitative segregation of wheat kernels containing exit holes, thus significantly reducing the quantity of material to be examined and hence the time required to complete the examination. Kernols containing only feeding punctures apparently tend to remain with whole or non insect-emerged kernels. The commercial apparatus used in this study is shown in Fig. 1.

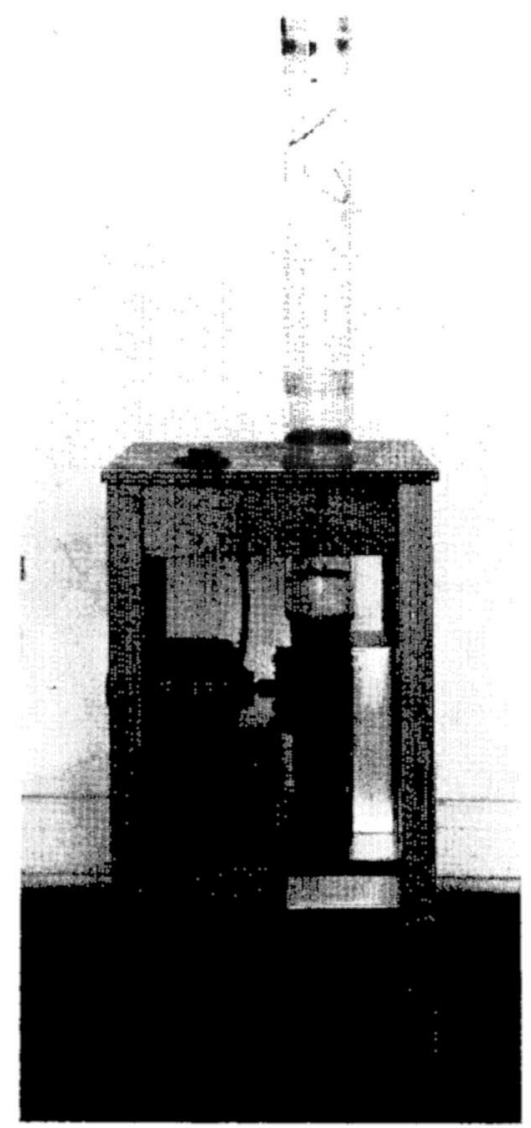

FIti. 1.-Sied blowing deviee used to separate insect-cmerged kernels. Noter separater values in column.

Since the blowing devire is "designed primarily to separate grain and seeds of different size and shape, it is necessary beforehand to make a rough separation of the infested sample into its component kernel sizes by sieving. Usually only $1 . w 0$ sieves are required, since for normal wheat the separations obtained with $\mathrm{N}_{0.8}$ and No.9 mesh sieves are adequate. The fractions obtained in this manner are then blown separately.

Evidence of the kind of separation achieved by this blowing technic 

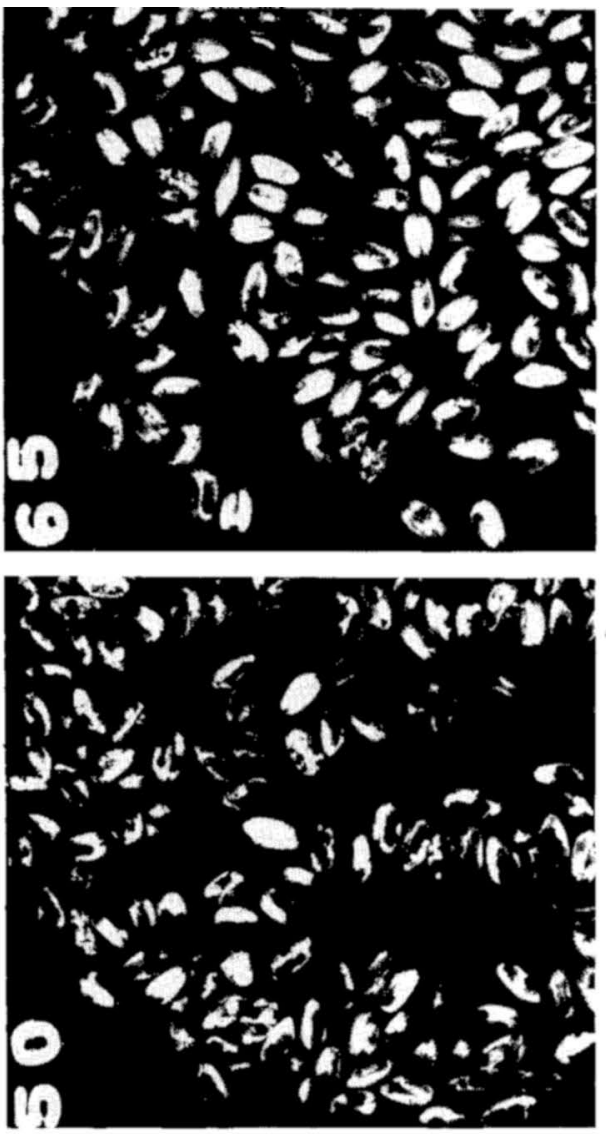

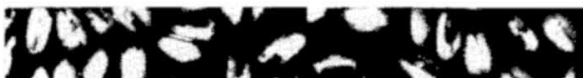

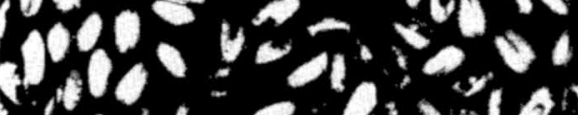
$0: 10=0,040$

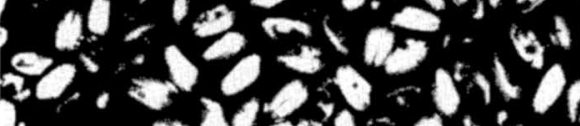
$20-2=0 \times 1=$

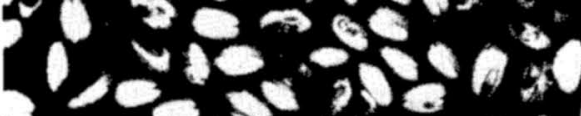
Cos -10

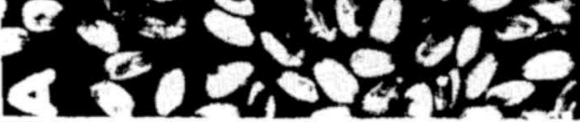

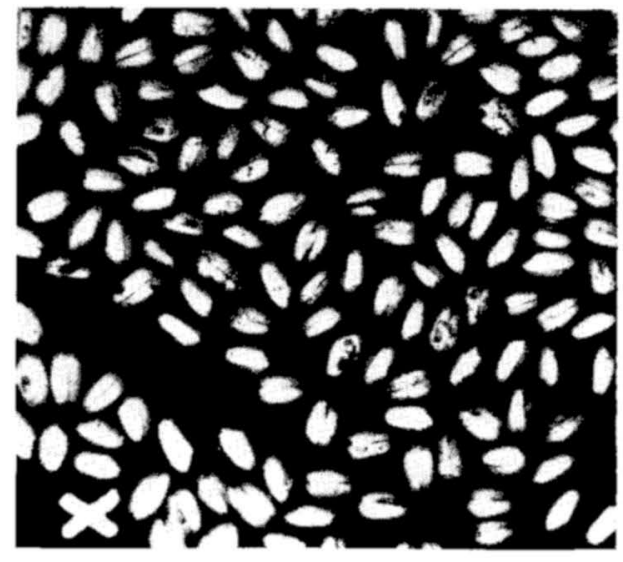

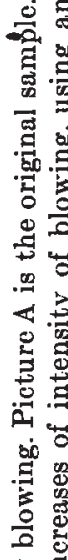
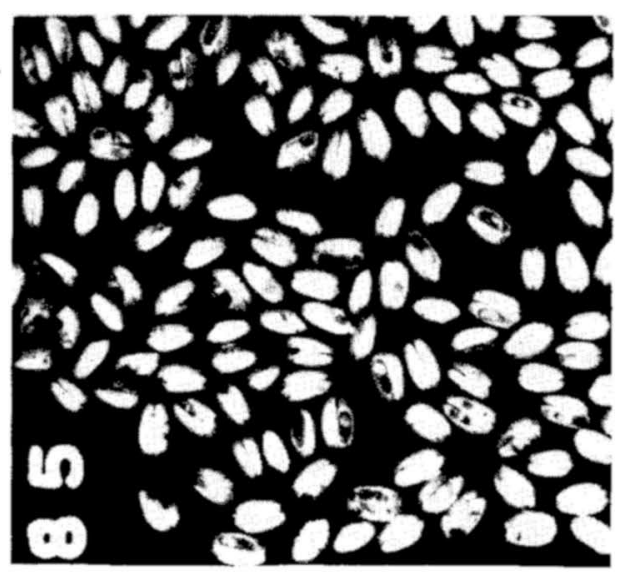

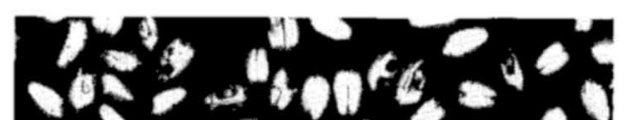
$+0 \%$ sos. $^{\circ}$ $n+108+2 \% 30$ $\therefore+1,19=0.18$

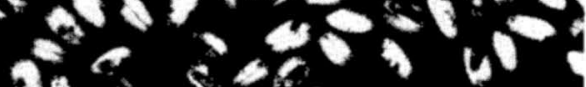
at 040.0 $125 x^{2}+2$ 

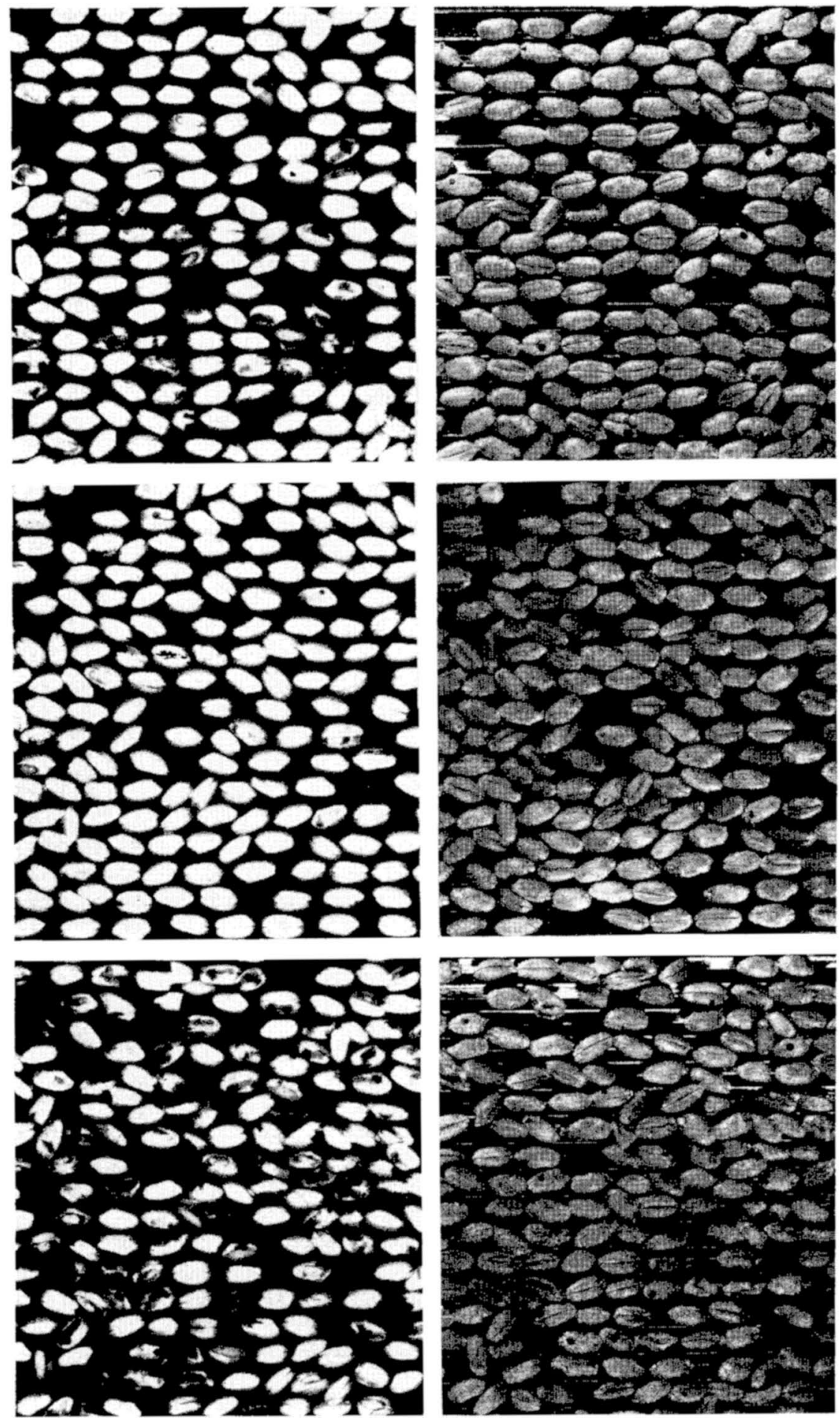

Fin. 3.- Radiographs and ordinary photographs of a onc-step separation of insect-emerged kernels from a sample of infested wherat. The left vertical row of radiographs (top to bottom) shows the original sample, the revidue after blowing, and the material removed by blowing respectively. The photographs on the right are of the precise field shown in the radiographs immediately to the left. 
appears in Figs. 2 and 3. The series of radiographs in Fig. 2 includes an $\mathrm{X}$-ray picture of the original sample of infested grain (A), in which various stages of infestation due to rice weevil, including numerous insect-emerged kernels, are shown. The subsequent pictures of this series are of fractions recovered from the original sample by progressively increasing the intensity of blowing. It is to be noted that virtually all the insect-emerged kernels are removed in the first two fractions, marked 50 and 65. This operation, while not precise, does produce an excellent separation of insect-emerged kernels from those in which no emergence has occurred.

The pictures in Fig. 3 provide an indication of the separation achieved with a single setting of the blower on a sample of mixed wheat containing various degrees of internal infestation. The vertical row of pictures on the right in Fig. 3 are ordinary photographs of the identical portions of the samples shown in the radiographs immediately to the left. In the left row, the radiograph at the top shows a portion of the original sample, and the radiograph at the bottom is representative of the material removed, which in this case constituted 22 per cent of the original 100 gram sample. This fraction contained nearly all the insect-emerged kernels present in the original sample. The $\mathrm{X}$-ray picture in the center is of the residue remaining after blowing, which constituted 78 per cent of the original sample.

The sieving and blowing of grain samples in the simplemanner outlined achieves a concentration of the insect-emerged kernels into a fraction of the original sample, in which detection of the kernels with exit holes is relatively quick and easy. An apparatus designed specifically for this purpose would probably produce an even better separation. The efficiency with which a concentration of insect-emerged kernels was achieved from the samples used in this study, which contained infestation far in excess of that normally found in commercial grain, indicates that the insectemerged kernels in commercial samples could be removed in a much smaller fraction. It would appear, therefore, that this technic of concentrating the defective kernels speeds up the exit hole inspection procedure in commercial samples by a factor of ten or better.

\section{REFERENCES}

(1) Mrlner, M., Milling Production, Jan. (1951).

(2) Reed, G. L., Harris, K. L., KepPel, G. E., Nicholson, J. F., Smith, F. R., Yakowitz, M. G., Akers, J. C., Kurtz, O. L., Milner, M., and Munday, W. H., This Journal, 36, 138 (1953).

(3) Harris, K. L., Nicholson, J. F., Randolph, L. K., and Trawick, J. L., ibid., 35,115 (1952).

(4) Apt, A. C., Milling Production, May (1952).

(5) Milner, M., Barney, D. L., and Shellenberaer, J. A., Science, 112, 791 (1950).

(6) Milner, M., Lee, M. R., and Katz, R., J. Econ. Entomol., 43, 933 (1950). 
1070 Association of OFFICIAL AGRicultural CHEMists [Vol. 36, No. 4

(7) — Food Technology, 6, 44 (1952).

(8) Milner, M., Katz, R., Lee, M. R., and Pyle, W. B., Cereal Chem., 30, 169 (1953).

(9) Adams, R. E., Wolfe, J._E., Milner, M., and Shellenberger, J. A., Science, 118, 163 (1953). 